\title{
TRISOMY FOR THE LONG ARM OF THE CHROMOSOME 18 DUE TO DE NOVO 18/21 TRANSLOCATION ${ }^{1}$
}

\author{
Junji Kameyama,*,2 Masato Tsurusawa,* Hiroyuki Nakano,* Sumita Shimizu,* \\ Rokuro OKUdA, ${ }^{*}$ Masuji Morita, ${ }^{* *}$ and Tatsuo ABE** \\ *Department of Pediatrics, University of Kyoto School of Medicine, Kyoto, Japan \\ **Department of Preventive Medicine, Kyoto Prefectural University of Medicine, Kyoto, Japan
}

Summary A case of de novo $18 / 21$ translocation resulting in $18 \mathrm{q}$ trisomy was described. Based on both G- and C-bandings, the patient's karyotype was identified as $46, \mathrm{XX}, \mathrm{t}(18 ; 21)(\mathrm{p} 11 ; \mathrm{q} 11)$. Her clinical feature fullfilled almost all criteria of the 18 trisomy syndrome reported.

\section{INTRODUCTION}

Structural chromosome rearrangements resulting in 18 trisomy syndrome have been in either inherited or de novo type described rarely (Hamerton, 1970; Neu et al., 1976).

This report concerns with a girl with a clinical stigmata of 18 trisomy syndrome (Edwards et al., 1960), who was found to be trisomic for the long arm of chromosome 18 due to de novo 18/21 translocation.

\section{CASE REPORT}

The proposita, O.T., was born as a second child to a 27 -year-old mother and a 32-year-old father. At birth, she weighed $2,000 \mathrm{~g}$. The pregnancy was uneventful except for maternal exposure to radiation at 36 weeks. At delivery, the amniotic fluid was clear and polyhydroamnion was not present. Her apgar score was 5 and her first breathing was delayed 2 min. She was admitted to our hospital $3 \mathrm{hr}$ later after the birth.

On admission, she was in a moribund state with dyspnea, extreme cyanosis and frequent clonic convulsions. Physical examination revealed such multiple abnormalities as prominent occiput, wide fontanels, low-set and malformed ears, lagophthalmus, colobomata of the iris, narrow palatal arch, micrognathia, overlapping of the index finger over the third and the fifth finger over the fourth, simple arches on 10 fingertips, short dorsiflexed hallux, rocker-bottom feet, small pelvis, limited hip

Received February 10, 1977

${ }^{1}$ Supported in part by a grant from the Ministry of Health and Welfare, Japan.

${ }^{2}$ Present address: of the first author: Dr. J. Kameyama. Department of Pediatrics, Red Cross Hospital, Tenman-cho, Takayama, Japan. 
abduction, short sternum. The calculated gestational age from Dubowitz development score was 35 weeks. She had a week cry and poor sucking and decreased Moro reflexes.

\section{Laboratory findings}

Routine and metabolic screening tests of urine were normal. Serum blood sugar level was extremely low $(14 \mathrm{mg} / \mathrm{d} 1)$. Relative hypogammaglobulinemia was demonstrated by serum electrophoresis and serum immunoglobulins were low for her age (IgG, 472mg/dl; IgA, 27mg/dl). Anemia and cardiac enlargement with increased pulmonary vascularity developed at 1 month of age. Intravenous pyelogram showed upper deviation of the both kidneys. Roentogenogram of extremities revealed no abnormalities.

\section{Clinical course}

Clonic convulsions accompanied by hypoglycemia appeared. The convulsions were resistant to the administration of glucose. Respiratory distress with cyanosis and moist râles of the lung persisted for life. The midsystolic blowing murmur was recognized along the left sternal border at 7 days of age. The patient developed congestive heart failure and died of complication of pneumonitis.

\section{AUTOPSY FINDINGS}

Malformations of the central nervous system and the heart were present. Encephalomalacia was found at the left and right temporal lobe. The cerebellum was hypoplastic. As for the heart an interventricular septal defect of $0.8 \mathrm{~cm}$ in diameter and patent ductus arteriosus $(0.3 \times 0.2 \mathrm{~cm})$ were present. There were eventrations of diaphragms with thin membranes because of upper deviations of both kidneys. The thymus was hypoplastic for her age.

\section{CYTOGENETIC FINDINGS}

Cytogenetic studies were carried out from lymphocytes cultures of the patient and her parents with our usual methods (Abe et al., 1975). G- and C-banded metaphase plates were obtained by the methods described by Nakagome et al. (1973) and Sumner (1972), respectively.

Both parents showed normal chromosome constitution. Examination of the proposita revealed a complement of 46 chromosomes with an extra chromosome comparable in size to No. 16 and a missing chromosome in group G. Analysis of G-banded karyotypes exhibited a reciprocal translocation between chromosomes 18 and 21 (Fig. 1). Therefore, the patient revealed to be trisomic for the long arm of chromosome 18. In Fig. 2 partial G- and C-banded karyotypes are shown. Analysis of a G-banded figure enabled us to confirm that almost entire segments of chromo- 


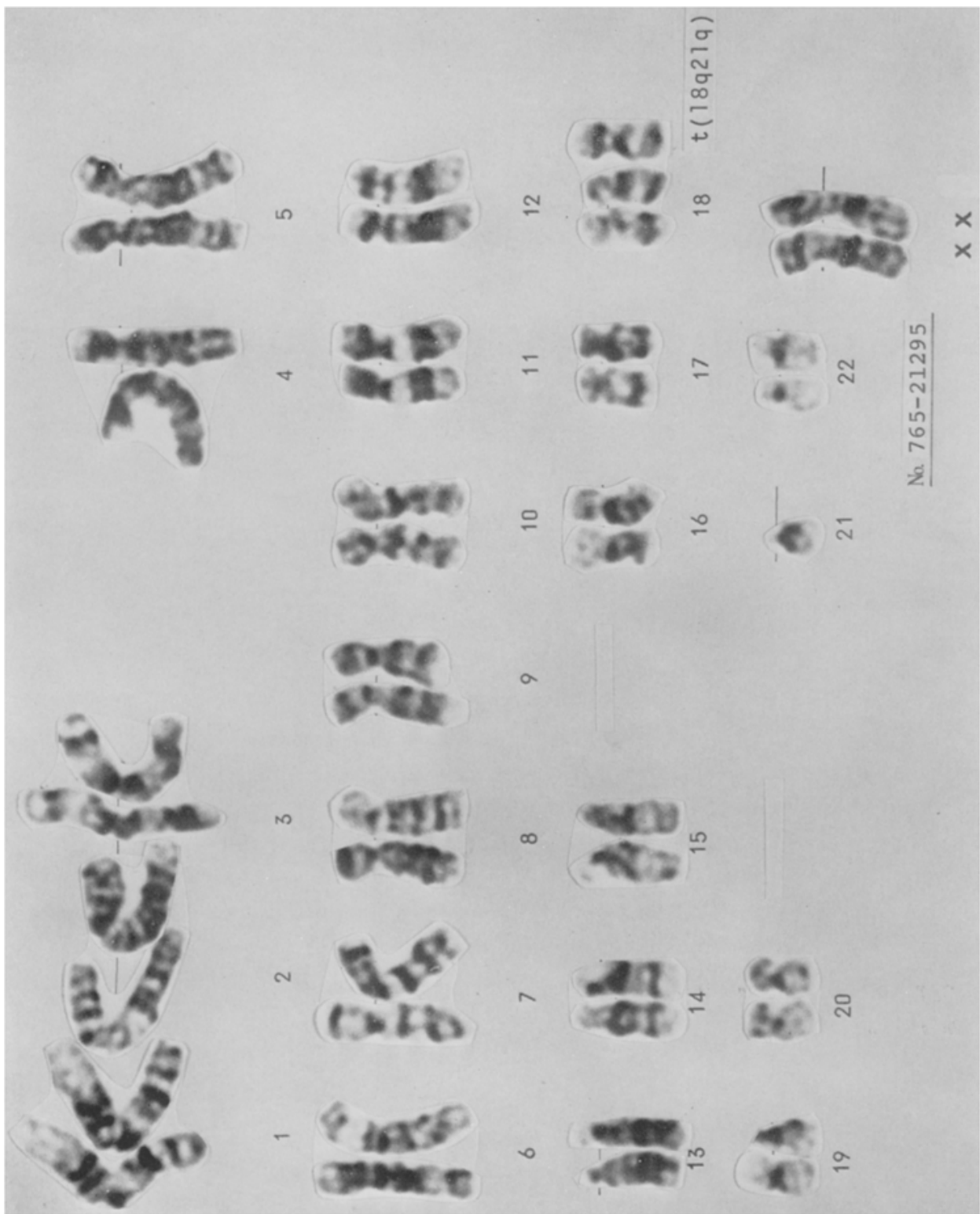

Fig. 1. G-stained karyotype of the proposita with $18 / 21$ translocation 18 trisomy syndrome.

some 21 and also entire long arm and the centromere of chromosome 18 were involved in the translocation suggesting the breaks occurred at near sites of the centromere. In addition, the translocation chromosome had a similar morphology to the chromosome 18 in regard to the size and/or the location of constitutive heterochromatin. 


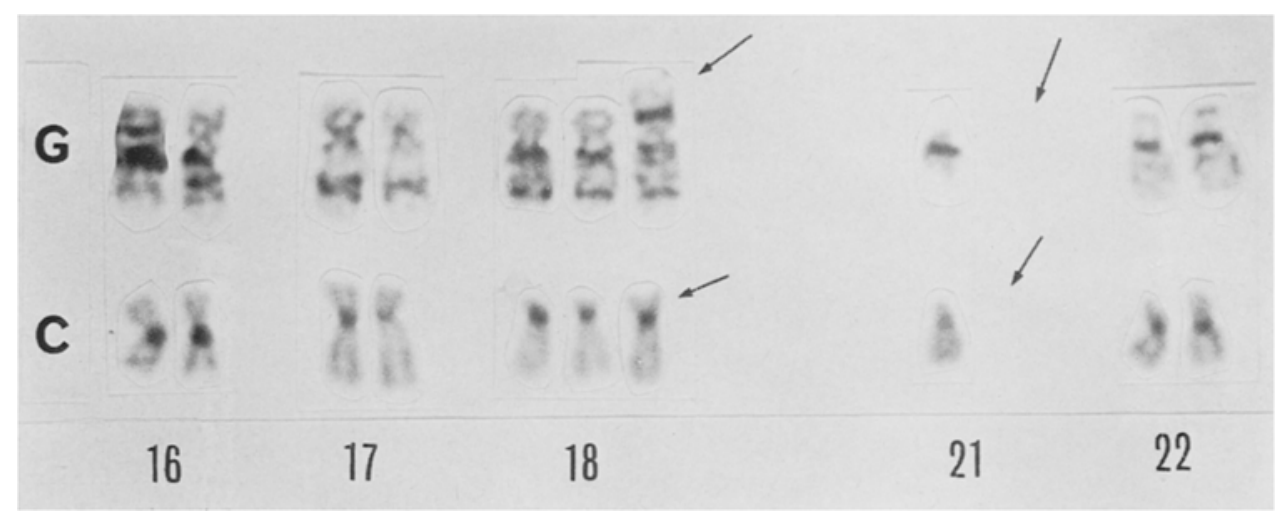

Fig. 2. G- and C-stained partial karyotypes of the proposita. Arrow indicates the transiocation, $\mathrm{t}(18 ; 21)(\mathrm{p} 11 ; \mathrm{q} 11)$.

These observations suggested that the breakpoints were localized to the bands $18 \mathrm{p} 11$ and $21 \mathrm{p} 11$, respectively. Therefore, her karyotype could be described as $46, \mathrm{XX}, \mathrm{t}$ $(18 ; 21)(\mathrm{p} 11 ; \mathrm{q} 11)$.

\section{DISCUSSION}

In 1960 Edwards et al. described the first case of E-trisomy. Patau et al. (1960) reported a similar case with E-trisomy and identified the trisomic chromosome as No. 18. Based on various population cytogenetic studies, an incidence of 18-trisomy syndrome was calculated at about $8.2 \times 10^{-5}$ live births in newborns among general populations (Hamerton, 1970).

Concerning translocation or partial $18 \mathrm{q}$ trisomy resulting in Edwards' syndrome the incidence seems to be far less frequent. Only about 15 cases appeared in the literature sporadically in the past 2 decades (Neu et al., 1976). Among them there are 4 cases with 18/G translocation 18 trisomy(Koch et al., 1968; Cohen et al., 1972; Dziekanowska et al., 1976; Neu et al., 1976), in which 8/21 translocation was identified in 2 cases (Cohen et al., 1972; Neu et al., 1976). In the case of Neu et al. (1976), the translocation chromosome has somewhat different morphology from ours with elongation of its centromeric region. They confirmed that the chromosome resulted from translocation between $18 \mathrm{q}$ and a whole chromosome 21 , including its satellite region. In the present case the translocation may be reciprocal. If breaks occurred at both $\mathrm{p} 11$ and $\mathrm{q} 11$ locations of chromosomes 18 and 21 , respectively, two derivative chromosomes could be produced: $\operatorname{der}(18 ; 21)(18 \mathrm{qter} \rightarrow 18 \mathrm{p} 11:: 21 \mathrm{qter} \rightarrow 21 \mathrm{q} 11)$ and der(18;21) (18pter $\rightarrow 18$ p11::21 qter $\rightarrow 21 \mathrm{q} 11)$. Since the latter chromosome or chromosome segments corresponding to this chromosome was not found, she was trisomic for only the long arm and the centromere of chromosome 18. Also she was monosomic in regard to the short arm of chromosome 21. 
Clinical features of the present case as most of the published cases with $18 \mathrm{q}$ trisomy revealed to be almost the same with the regular type of 18 trisomy syndrome except for lagophthalmus and decumbency. Hypoglycemia with convulsions seen in our case was reported by Orzalest et al. (1967).

Since both parents exhibited normal karyotypes, chromosome abnormalities found in the present case occurred at paternal or maternal meiosis: at first nondisjunction occurred at chromosome 18 and was followed by a reciprocal translocation between chromosomes 18 and 21 and vice versa.

\section{REFERENCES}

Abe, T., Morita, M. and Kawai, K. 1975. Cd-banding of human chromosomes observed in the Cbanding procedure. Lancet ii $981-982$.

Cohen, M. M., Finch, A. B. and Lubs, H. A. 1972. Trisomy 18 with an E/G translocation/46, XY, 21-, t(21q18q)/. Ann. Génét. 15: 45-49.

Dziekanowska, D., Dziuba, P. and Sobansky, T. 1976. The trisomy 18 syndrome with an E/G translocation. Human Genet. 31: 347-349.

Edwards, J. H., Harnden, D. G., Cameron, A. H., Crosse, V. M. and Wolff, O. H. 1960. A new trisomic syndrome. Lancet i: 787-790.

Hamerton, J. L. 1971. Abnormalities of the autosomes-group E (16-18 group-Denver Conference). In Human Cytogenetics, Vol. II, Clinical Genetics, Academic Press, New York-London, pp. 276-309.

Koch, G., Gröpl, U., Mayer-Robisch, M. and Schwanitz, G. 1968. E/G-Translokation bei Vater und Sohn. In Anthropologie und Humangenetik, Fischer, Stuttgarrt, pp. 176-183.

Nakagome, Y., Iinuma, K. and Taniguchi, K. 1973. Points of exchanges in a human No. 5 ring chromosome. Cytogenet. Cell Genet. 12: 35-39.

Ozalest, M., Renzulli, F. and Ferrante, E. 1967. Trisomy 18 and neonatal hypoglycemia. Lancet ii: 1211.

Patau, K. A., Therman, E., Smith, D. W. and DeMars, R. I. 1961. Trisomy for chromosome No. 18 in man. Chromosoma 12: 280-285.

Sumner, A. T. 1972. A simple technique for demonstrating centromeric heterochromatin. Exp. Cell Res. 75: 304-306. 